\title{
Endoscopic submucosal dissection with circumferential incision versus tunneling method for treatment of superficial esophageal cancer
}

\author{
Tarso Magno Leite RIBEIRO ${ }^{1,2}$, Vitor N ARANTES ${ }^{1,3}$, Jonas Augusto RAMOS ${ }^{2}$, Peter V DRAGANOV ${ }^{4}$, \\ Dennis YANG ${ }^{4}$ and Roberto Gardone GUIMARÃES ${ }^{1,3}$
}

Received: 28 October 2020

Accepted: 2 January 2021

\begin{abstract}
Background - Endoscopic submucosal dissection (ESD) of esophageal superficial neoplasm is associated with a high en bloc R0 resection rate and low recurrence. Objective - We aim to compare the performance and clinical outcomes of ESD via ESD after circumferential incision (ESD-C) versus submucosal tunneling (ESD-T). Methods - Single-center retrospective analysis of all consecutive patients who underwent ESD for superficial esophageal cancer, between 2009 and 2018. ESD-T was defined as the technique of making the mucosal incisions followed by submucosal tunneling in the oral to anal direction. ESD-C consisted of completing a circumferential incision followed by ESD. Main study outcomes included en bloc and R0 resection rates. Secondary outcomes included procedural characteristics, curative resection rate, local recurrence and adverse events. Results - A total of 65 procedures (23 ESD-T and 42 ESD-C) were performed for ESCC (40; 61.5\%) and BE-neoplasia (25; 38.5\%). There were no statistically significant differences between patients who underwent ESD-T versus ESD-C in en bloc ( $91.3 \%$ vs $100 \%, P=0.12), \mathrm{R} 0(65.2 \%$ vs $78.6 \%, P=0.24)$, curative resection rates $(65.2 \%$ vs $73.8 \%, P=0.47)$ and mean procedure time (118.7 min with vs $102.4 \mathrm{~min}, P=0.35)$. Adverse events for ESD-T and ESD-C were as follows: bleeding ( 0 versus $2.4 \% ; P=0.53)$, perforation $(4.3 \%$ vs $0 ; P=0.61)$, esophageal stricture $(8.7 \%$ versus $9.5 \% ; P=0.31)$. Local recurrence was encountered in $8.7 \%$ after ESD-T and 2.4\% after ESD-C $(P=0.28)$ at a mean follow-up of 8 and 2.75 years, respectively $(P=0.001)$. Conclusion - ESD-T and ESD-C appear to be equally effective with similar safety profiles for the management of superficial esophageal neoplasms. Keywords - Endoscopic submucosal dissection; superficial esophageal neoplasm; esophageal cancer; squamous cell cancer; Barrett's esophagus.
\end{abstract}

\section{INTRODUCTION}

Endoscopic submucosal dissection (ESD) was initially developed in Japan for the removal of early gastric cancer ${ }^{(1,2)}$. The distinct advantage of ESD is the ability to perform en bloc resection of lesion regardless of size, thereby providing an optimal histopathological specimen. Furthermore, ESD has a substantially lower morbidity than surgical esophagectomy ${ }^{(3)}$ and provides higher $\mathrm{R} 0$ and curative resection rates compare to endoscopic mucosal resection $(\mathrm{EMR})^{(4-15)}$. As such, ESD is currently endorsed by the European Society of Gastrointestinal Endoscopy (ESGE) and in a recent American Gastroenterology Association (AGA) clinical practice update for the removal of select superficial esophageal neoplasms ${ }^{(8,9)}$.

Nonetheless, the adoption of ESD in the esophagus, particularly in the West, has been slower due to technical reasons ${ }^{(10-12)}$. For example, the esophageal wall is thinner than the stomach and the intraluminal space is more restricted, limiting the ability to work in retroflexion. Furthermore, scope control can be impaired by heartbeat or breathing patterns ${ }^{(13)}$. Given these technical challenges, steep learning curve and the lower incidence of superficial esophageal neoplasms, esophageal ESD is mostly restricted to tertiary care centers ${ }^{(10-12,14-18)}$.
There are two main technical approaches for ESD in the esophagus: conventional ESD via circumferential incision (ESD-C) and ESD via tunneling method (ESD-T). With ESD-C, a circumferential mucosal incision is first completed around the outer margins of the lesion followed by submucosal dissection ${ }^{(19)}$. Conversely, with ESD-T, two small separate mucosal incisions (distal and proximal margins of the lesion) are performed first. The endoscope is then inserted into the mucosal incisional opening in the oral side and submucosal tunneling is performed deep to the lesion towards the caudal side. Theoretically, this technique diminishes the dispersion of the submucosal lift during the procedure ${ }^{(11,20)}$. The study aimed to compare the performance and clinical outcomes of ESD-C versus ESD-T.

\section{METHODS}

\section{Study design}

This is a single-center retrospective study based on prospectively collected data on consecutive patients who underwent esophageal ESD between October 2009 and December 2018 at Clinics Hospital, Federal University of Minas Gerais. Indications for esophageal ESD were based on the Japan Esophageal Society (JES)

Declared conflict of interest of all authors: Draganov PV, consultant for: Olympus, Boston Scientific Corporation, Cook Medical, MicroTech, Merit, Lumendi, Fujifilm. Yang D: consultant for Boston Scientific Corporation, Lumendi, Steris. Ribeiro TML, Arantes VN, Ramos JA, Guimarães RG: no conflict of interest.

Disclosure of funding: no funding received

${ }^{1}$ Universidade Federal de Minas Gerais, Faculdade de Medicina, Instituto Alfa de Gastrenterologia, Belo Horizonte, MG, Brasil. ${ }^{2}$ Universidade Federal de São João Del Rei, MG, Brasil. ${ }^{3}$ Hospital Mater Dei Contorno, Unidade de Endoscopia, Belo Horizonte, MG, Brasil. ${ }^{4}$ University of Florida, Division of Gastroenterology, Hepatology and Nutrition, Gainesville, Florida, USA.

Corresponding author: Tarso Magno Leite Ribeiro. E-mail: tarsomagno@ufsj.edu.br 
and European Society of Gastrointestinal Endoscopy (ESGE) guidelines $^{(9,21)}$. Preoperative staging included high resolution endoscopy (HRE) with virtual chromoendoscopy (FICE, Flexible Spectral Imaging Colour Enhancement, Fujifilm Japan) and 0.8\% Lugol staining plus chest computed tomography and endoscopic ultrasound for staging (in selected cases). Exclusion criteria were advanced tumors or presence of a non-lifting sign. ESD procedures were performed by a single endoscopist (Arantes VN), with more than 10 years of ESD practice and over 230 operations.

The main study outcomes were the comparison of en bloc and $\mathrm{R} 0$ resection rates between the two techniques. Moreover, the following secondary outcomes were assessed: demographic data, clinical and pathological characteristics, procedure duration, curative resection rate, local recurrence, and adverse events. Follow-up HRE was scheduled from 3 to 6 months after the ESD, and annually thereafter.

\section{Endoscopic Procedure}

In all cases, ESD was carried out under general anesthesia utilizing a single-channel therapeutic gastroscope (RD450 Fujifilm Co., Japan) fitted with a cone-shaped distal attachment at the tip (ST-hood, Fujifilm Co., Japan), Flush Knife ball-tipped 1.5 (Fujifilm Co., Japan), water-jet pump infusion (JW2; Fujifilm Co., Japan) and electrosurgical generator VIO 300D (ERBE, Turbingen, Germany). Markings were placed outside tumor borders after target lesion assessment with virtual chromoendoscopy and Lugol staining in the cases of squamous cell dysplasia/cancer or $1.5 \%$ acetic acid chromoendoscopy for patients with Barrett's related neoplasia. The traction method was used for the procedures.

\section{Endoscopic submucosal dissection with circumferential incision (ESD-C)}

After a submucosal (SM) injection of $0.4 \%$ sodium hyaluronate (Adaptis Fresh, Legrand, Brazil), a mucosa incision was initiated at the oral margin of the lesion, followed by an incision along with one of the lateral margins and next at the caudal margin of the tumor, resulting in a configuration of the character " $C$ ". Afterwards, a partial SM dissection was carried out from an oral-anal direction. Thereafter the remaining mucosa at the lateral side of the lesion was incised until the entire circumference of the tumor was completely opened, creating a mucosa island. After complete mucosal incision, further injections of viscous solution were performed followed by oral-anal SM dissection. FIGURES 1 and 2 illustrate ESD-C technique.

\section{Submucosal tunnel dissection (ESD-T)}

ESD-T is first performed with submucosal injection of $0.4 \%$ sodium hyaluronate at the caudal margin of the lesion, followed by a transverse mucosal incision to the deep submucosa creating a groove close to the muscular propria to set up for the endoscopic tunnel. The same process is repeated at the oral margin of the lesion. Submucosal dissection is then performed in the cranial-caudal direction forming a tunnel. When the distal incision is reached, the dissection is extended laterally on both sides, incising the lateral boundaries of the tumor. Repeat injections are performed, and the dissection is expanded on each side of the tumor until a complete resection is reached. FIGURE 3 and 4 illustrate ESD-T technique.

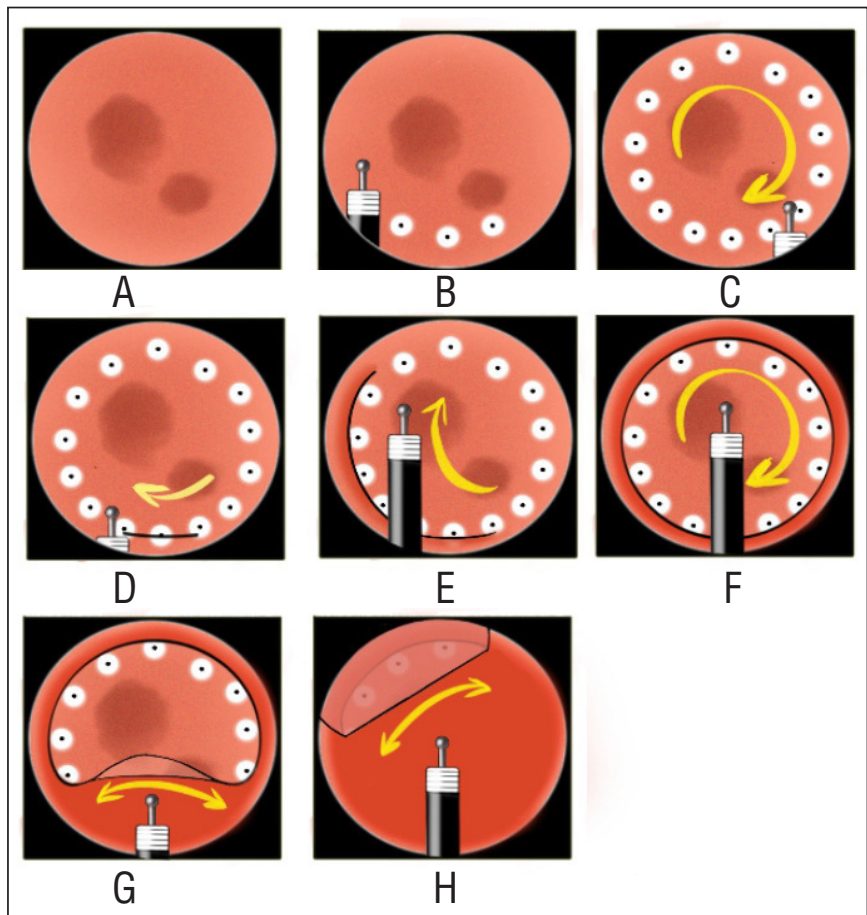

FIGURE 1. Schematic representation of endoscopic submucosal dissection with circumferential incision.

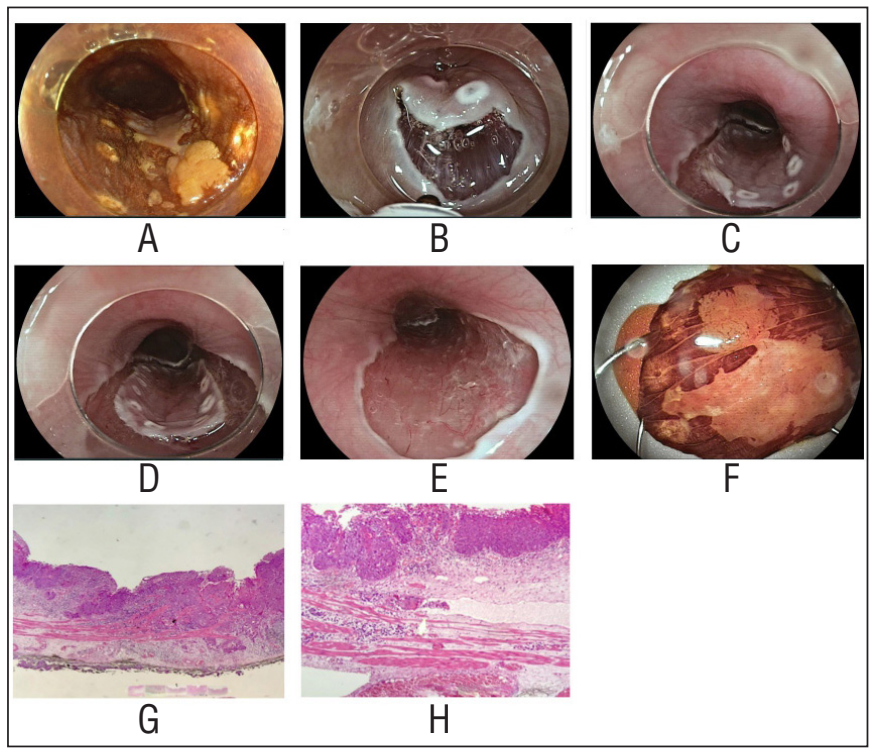

FIGURE 2. Illustrative case of endoscopic submucosal dissection with circumferential incision (ESD-C). A: A flat-elevated type 0IIA unstained lesion in the esophagus. Markings were placed. B: After submucosal injection oral mucosal incision is started. C: Semi-circumferential incision addressing gravity side is performed with a configuration of " $\mathrm{C}$ " character. D: After submucosal trimming to some extension, circumferential incision is finished. E: Complete tumor resection is achieved. F: Specimen is fixed and stained with lugol. Note unstained lesion surrounded by lugol stained margins. G: Histology revealed moderately differentiated squamous cell carcinoma with shallow invasion of submucosal layer up to 200 micrometers (SM1) with free radial and deep margins (R0 resection). H: Histology also disclosed positive vascular invasion and tumoral budding. Resection was considered non-curative and patient was referred to oncological adjuvant therapy. 


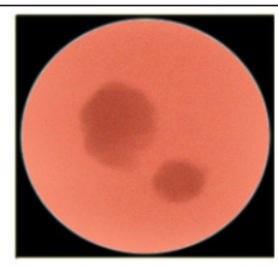

A

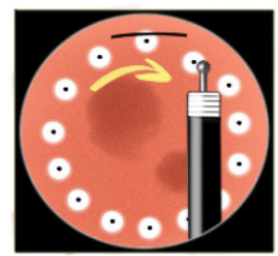

D

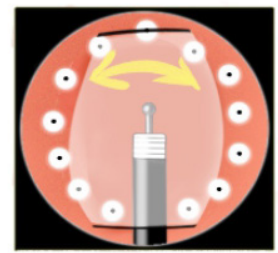

G

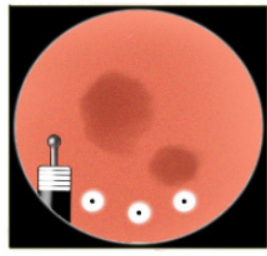

B

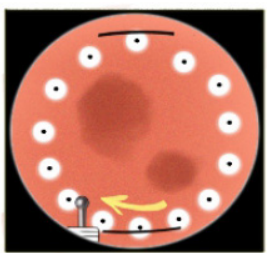

$\mathrm{E}$

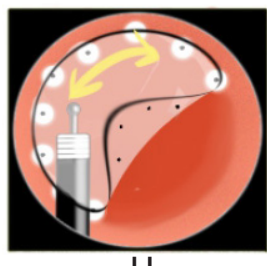

$\mathrm{H}$

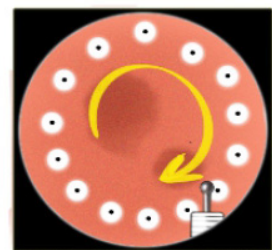

C

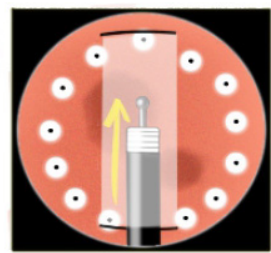

$\mathrm{F}$
FIGURE 3. Schematic representation of endoscopic submucosal tunnel dissection

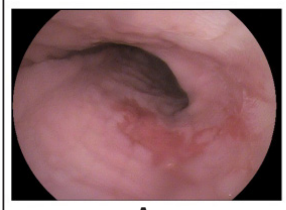

A

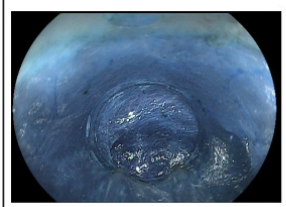

D

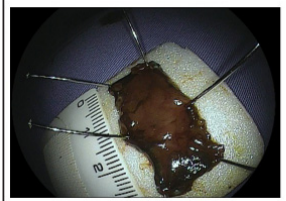

G

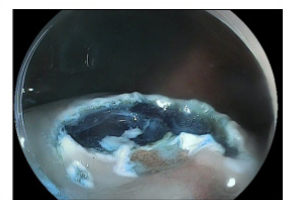

B

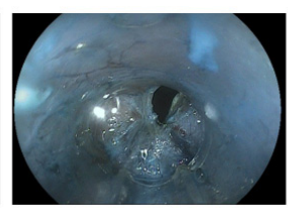

$\mathrm{E}$

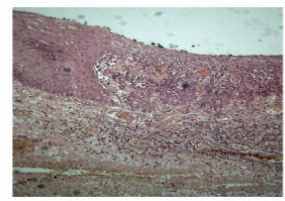

$\mathrm{H}$

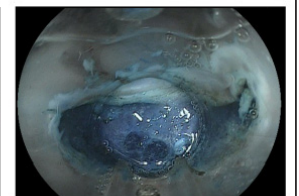

C

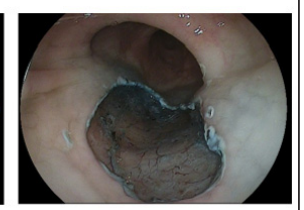

$\mathrm{F}$
FIGURE 4. Illustrative case of endoscopic submucosal tunnel dissection (ESD-T). A: A flat type OIIB lesion with redness in the esophagus. B: After placing markings and submucosal injection, anal mucosal incision is performed to set up tunnel distal limit. C: Oral incision is performed to start tunneling. D: Tunneling dissection from oral to anal direction. E: Anal incision is reached through the tunnel and a window is opened visualizing the lumen. F: Complete tumor resection is achieved. G: Specimen is fixed, $3 \mathrm{~cm}$ in size. $\mathrm{H}$ : Intraepithelial high-grade neoplasia limited to M1 with free margins is revealed in histology. Curative R0 resection.

\section{Definitions}

Tumor morphology was described according to Paris classification $^{(22)}$. The tumor size was estimated in comparison to an opened biopsy forceps with $7 \mathrm{~mm}$ in size. En bloc resection was considered when the endoscopically visible lesion was removed in one piece. $\mathrm{R} 0$ resection was defined for esophageal squamous cell carcinoma (ESSC) when the tumor was resected en bloc and both lateral and deep margins were free of tumor. For BE neoplasia, $\mathrm{R} 0$ resection was defined as en bloc resection and the highest-grade histology not present at the lateral and deep margins. Tumor location in the esophagus was divided into superior third (from superior sphincter to $23 \mathrm{~cm}$ from incisors), middle third ( $23 \mathrm{~cm}$ to $30 \mathrm{~cm}$ from incisors), and inferior third (from 30 $\mathrm{cm}$ to esophago-gastric junction). Luminal extension of tumor resection was also divided according to the endoscopic inspection of the post-ESD defect in less than $50 \%$ of the circumference, between $50 \%$ and $75 \%$, and over $75 \%$ of the circumference. Recurrence was defined when a recurrent tumor with histological confirmation (low-grade/high-grade dysplasia, squamous cell cancer, or adenocarcinoma) at the resection site was observed in the follow-up examination. In ESSC, curative resection was considered for $\mathrm{R} 0$ resection with tumor invasion up to M2 (lamina propria), without lymphovascular invasion, and in those well-differentiated lesions with M3/SM1 tumor depth $(\leq 200 \mu \mathrm{m})$ without lymphovascular invasion ${ }^{(9)}$. Curative resection of $\mathrm{BE}$ associated lesions, was defined as $\mathrm{R} 0$ resection of any dysplastic lesion, and also well or moderately differentiated adenocarcinoma without lymphatic or vascular invasion and submucosal invasion depth up to $500 \mu \mathrm{m}$ (T1Bsm1 $)^{(9)}$. When the criteria for curative resection were not achieved, additional therapies such as chemotherapy, radiotherapy, or surgery were considered, according to tumor characteristics and staging, as well as the patient's performance status and willingness to undergo esophagectomy or oncological therapy. Adverse events were defined according to the ASGE lexicon ${ }^{(23)}$ when it prevented completion of the planned procedure and/or resulted in prolongation of existing hospital stay, another procedure (repeated endoscopy needing sedation/ anesthesia or surgery), or subsequent medical consultation. These adverse events included esophageal perforation, delayed bleeding, bacteremia, sepsis, pneumothorax or pleural effusions.

\section{Statistical analysis}

A descriptive analysis of data was performed with frequency and proportion for categorical and average variables, standard deviation, median and mean \pm SD for continuous variables. Pearson's chi-square test was used to evaluate the association and a comparison of continuous variables, Student's $t$-test for variables with normal distribution and Mann Whitney's test for variables that do not follow normal distribution were used. Analyzes were performed on STATA software (Stata Corporation, College Station, Texas) version 12.0, considering a 5\% significance level.

\section{RESULTS}

A total of 65 esophageal ESD procedures were performed during the study period. The subjects were distributed into two groups: ESD-T: 23 interventions carried out from 2009 to 2012 and ESD-C: 42 operations executed from 2012 to 2018. The follow-up was $101 \pm 8.5$ months for ESD-T and $36 \pm 21.1$ months (mean \pm SD) for $\mathrm{ESD}-\mathrm{C}(P<0.001)$. TABLE 1 demonstrates that there were no 
TABLE 1. Comparative analysis of baseline characteristics.

\begin{tabular}{|c|c|c|c|c|}
\hline Characteristics & ESD-T & ESD-C & Total & $P$ value \\
\hline Procedures & 23 & 42 & 65 & \\
\hline Gender & & & & $0.317 * * *$ \\
\hline Male & $19(82.6 \%)$ & $30(71.4 \%)$ & $49(75.4 \%)$ & \\
\hline Female & $4(17.4 \%)$ & $12(28.6 \%)$ & $16(24.6 \%)$ & \\
\hline $\begin{array}{l}\text { Age (years old) } \\
\text { average } \pm S D\end{array}$ & $64.6 \pm 12.4$ & $64.8 \pm 9.8$ & $64.7 \pm 10.6$ & $0.947 *$ \\
\hline $\begin{array}{l}\text { Tumor size }(\mathrm{mm}) \\
\pm \mathrm{SD}\end{array}$ & $28.9 \pm 12$ & $35.8 \pm 19.9$ & $33.4 \pm 17.7$ & $0.380 * *$ \\
\hline \multicolumn{4}{|c|}{ Tumor location in the esophagus } & $0.165 *$ \\
\hline Superior third & $1(4.3 \%)$ & $6(14.3 \%)$ & $7(10.8 \%)$ & \\
\hline Middle third & $8(34.8 \%)$ & $20(47.6 \%)$ & $28(43.1 \%)$ & \\
\hline Inferior third & $14(60.9 \%)$ & $16(38.1 \%)$ & $30(46.2 \%)$ & \\
\hline \multicolumn{4}{|l|}{ Paris classification } & $0.773 *$ \\
\hline Elevated 0-IIa & $4(17.4 \%)$ & $12(28.6 \%)$ & $16(24.6 \%)$ & \\
\hline Flat 0 -IIb & $15(65.2 \%)$ & $24(57.1 \%)$ & $39(60.0 \%)$ & \\
\hline $\begin{array}{l}\text { Depressed } \\
\text { 0-IIc }\end{array}$ & $3(13 \%)$ & $5(11.9 \%)$ & $8(12.3 \%)$ & \\
\hline Mixed types & $1(4.3 \%)$ & $1(2.4 \%)$ & $2(3.1 \%)$ & \\
\hline \multicolumn{4}{|c|}{ Circumferential extension } & $0.147 *$ \\
\hline$<50 \%$ & $14(60.9 \%)$ & $15(35.7 \%)$ & $29(44,6 \%)$ & \\
\hline$\geq 50 \%<75 \%$ & $5(21.7 \%)$ & $16(38.1 \%)$ & $21(32.3 \%)$ & \\
\hline$\geq 75 \%$ & $4(17.4 \%)$ & $11(26.2 \%)$ & $15(23.1 \%)$ & \\
\hline Lesion type & & & & $0.129 *$ \\
\hline ESCC & $17(73.9 \%)$ & $23(54.8 \%)$ & $40(61.5 \%)$ & \\
\hline $\begin{array}{l}\text { BE-associated } \\
\text { neoplasia }\end{array}$ & $6(26.1 \%)$ & $19(45.2 \%)$ & $25(38.5 \%)$ & \\
\hline
\end{tabular}

ESD-T: endoscopic submucosal dissection tunneling; SD: standard deviation; BE: Barrett's esophagus; SCC: squamous cell carcinoma. *Chi square test. **Mann Whitney test. ***T-Student test.

significant differences in gender, age, tumor size, tumor location, Paris classification, and luminal extension between both groups. Histological assessment from ESD-T specimens revealed ESCC in $17(73.9 \%)$ lesions and dysplasia or adenocarcinoma associated with Barrett's esophagus in $6(26.1 \%)$ subjects. The ESD-C group's histological assessment demonstrated that $23(54.8 \%)$ lesions were ESCC and $19(45.2 \%)$ tumors were dysplasia or adenocarcinoma associated with BE. No statistical difference was noted between the histological assessment of both groups $(P=0.129)$. In a total of 25 lesions with Barrett's esophagus, 18 (72\%) were high-grade dysplasia and 7 (28\%) were adenocarcinoma.

TABLE 2 presents clinical outcomes of ESD procedures demonstrating no statistically significant difference between the two groups. En bloc resection rate, $\mathrm{R} 0$ resection rate and curative resection rate for ESD-T and ESD-C were respectively: $91.3 \%$ vs $100 \%(P=0.122), 65.2 \%$ vs $78.6 \%(P=0.241)$ and $65.2 \%$ vs $73.8 \%$ $(P=0.466)$. In relation to procedure duration, ESD-T lasted $118.7 \pm 50.8$ minutes from marking the lesion to final resection and ESD-C 102.4 \pm 40.4 minutes (mean \pm SD) $(P=0.351)$. Local tumor recurrence occurred in $8.7 \%$ treated with the tunneling technique and $2.4 \%$ with the conventional technique $(P=0.284)$.
TABLE 2. Comparative analysis of ESD outcomes

\begin{tabular}{|c|c|c|c|c|}
\hline Characteristic & ESD-T & ESD-C & Total & $P$ value \\
\hline $\begin{array}{l}\text { Curative } \\
\text { resection }\end{array}$ & $15(65.2 \%)$ & $31(73.8 \%)$ & $46(70.8 \%)$ & $0.466 *$ \\
\hline $\mathrm{R} 0$ resection & $15(65.2 \%)$ & $33(78.6 \%)$ & $48(73.8 \%)$ & $0.241 *$ \\
\hline $\begin{array}{l}\text { En bloc } \\
\text { resection }\end{array}$ & $21(91.3 \%)$ & $42(100 \%)$ & $63(96.9 \%)$ & $0.122 * *$ \\
\hline $\begin{array}{l}\text { Procedure time } \\
(\mathrm{min}) \pm \mathrm{SD}\end{array}$ & $118.7 \pm 50.8$ & $102.4 \pm 40.4$ & $108 \pm 44.6$ & $0.351 * * *$ \\
\hline Recurrence & $2(8.7 \%)$ & $1(2.4 \%)$ & $3(4.6 \%)$ & $0.284 * *$ \\
\hline \multicolumn{4}{|c|}{ Tumor invasion depth } & $0.745 *$ \\
\hline $\mathrm{M} 1 / \mathrm{M} 2$ & $12(52.2 \%)$ & $21(50 \%)$ & $33(50.7 \%)$ & \\
\hline M3/SM1 & $9(39.1 \%)$ & $12(28.6 \%)$ & $21(32.3 \%)$ & \\
\hline $\mathrm{SM} 2 / \mathrm{SM} 3$ & $2(8.7 \%)$ & $9(21.4 \%)$ & $11(16.9 \%)$ & \\
\hline
\end{tabular}

Procedure-related complications

\begin{tabular}{lcccc} 
Bleeding & 0 & $2(4.8 \%)$ & $2(3.0 \%)$ & $0.536 * *$ \\
Perforation & $1(4.3 \%)$ & 0 & $1(1.5 \%)$ & $0.610 * *$ \\
Stenosis & $2(8.7 \%)$ & $4(9.5 \%)$ & $6(9.2 \%)$ & $0.310 *$ \\
\hline ESD-T: endoscopic submucosal dissection tunneling. *Chi square test. **Fisher test. ***Mann \\
Whitney test.
\end{tabular}

The depth of tumor invasion was similar in both groups $(P=0.745)$. ESD-T group lesions invaded M1/M2 in $12(52.2 \%)$ cases, M3 / SM1 in $9(39.1 \%)$ cases and SM2 in $2(8.7 \%)$ cases. ESD-C group presented M1/M2 invasion depth in $21(50 \%)$ subjects, M3/SM1 in $12(28.6 \%)$ individuals and SM2 invasion in $9(21.4 \%)$ patients. Regarding procedure-related complications, groups ESD-T versus ESD-C had respectively a bleeding rate of $0 \%$ and $4.7 \%,(P=0.53)$, perforation rate of $4.3 \%$ and $0 \%(P=0.610)$ and esophageal stricture rate of $8.7 \%$ and $9.5 \%$, $(P=0.310)$. Two patients from the ESD-C group (4.8\%) experienced more intense intraoperative bleeding, requiring mechanical hemostasis with endoclips. Two patients in the ESD-T group $(8.7 \%)$ and $4(9.5 \%)$ patients in the ESD-C group developed strictures that were treated successfully with endoscopic dilation. There was one case of esophageal perforation in the ESD-T group that did not prevent en bloc excision and was treated conservatively by endoclip closure, intravenous hydration, and antibiotics. There was no procedure-related mortality.

\section{DISCUSSION}

The optimal ESD approach for the resection of esophageal superficial neoplasia has not been well defined. In this study, we demonstrate similar clinical outcomes and safety profiles between consecutive patients who underwent either ESD-C or ESD-T. There are previous publications regarding ESD-T and ESD-C for the treatment of superficial esophageal neoplasms, however studies comparing these two techniques in human studies are $\operatorname{rare}^{(24,25)}$. In experimental settings, a randomized study in animal models demonstrated similar procedure time, en bloc resection, and adverse event rates between ESD-C and ESD-T. Notably, the study demonstrated that higher-quality deeper margins and thicker specimens were obtained with the submucosal tunneling method ${ }^{(25)}$. A recent study in humans reported by Li et al. compared short-term 
outcomes of ESD-C versus ESD-T dissection techniques for treating early ESCC in a total of 40 patients. The authors reported that ESD-T had a shorter dissection time $(P=0.047)$, but no difference was noted regarding the en bloc resection rate and $\mathrm{R} 0$ resection rate. Moreover, there was no significant difference in adverse events such as perforation, bleeding, or stenosis ${ }^{(24)}$.

The study included a predominantly male elderly population $(74.5 \%)$, with a median tumor size of $30 \mathrm{~mm}$, located mostly in the middle and lower thirds of the esophagus $(89.3 \%)$ and classified as type $0-\mathrm{IIb}$ of Paris in $60 \%$ of the cases. Regarding histological type, $61.5 \%$ were SCC and $38.5 \%$ dysplasia/adenocarcinoma type associated with BE. The higher proportion of SCC in this study is probably due to an ongoing screening program for esophageal early tumors in patients with head and neck cancer ${ }^{(26)}$.

In expert hands in Asian countries ESD has shown excellent results in the management of ESSC: en bloc resection rate around $83-100 \%$, R0 resection between $78-100 \%$, and a local recurrence rate of $0-2.6^{(1,2,4,8,10)}$. Results reported for Barrett's esophageal-associated lesions range from $90 \%$ to $100 \%$ of en bloc resection, R0 resections from $64 \%$ to $85 \%$, curative resections of early adenocarcinoma between $48 \%$ and $96 \%{ }^{(15,27-29)}$. A recently published meta-analysis by Yang et al. ${ }^{(30)}$ assessing BE-associated ESD showed the following results: en bloc resection rate $92.9 \%$ (95\% CI, 90.3\%-95.2\%), R0 resection 74.5\% (95\% CI 66.3\%-81.9\%) and curative resection $64.9 \%(95 \% \mathrm{CI} 55.7 \%-73.6 \%)$. The rates of perforation, bleeding and stenosis were $1.5 \%(95 \% \mathrm{CI}, 0.4 \%-3.0 \%)$, $1.7 \%(95 \% \mathrm{CI}, 0.6 \%-3.4 \%)$ and $11.6 \%(95 \% \mathrm{CI}, 0.9 \%-29.6 \%)$ respectively. During an average follow up of 22.9 months $(95 \% \mathrm{CI}$, $17.5-28.3)$ the incidence of recurrent lesions was $0.17 \%(95 \% \mathrm{CI}$, $0 \%-3 \%)$. The average procedure time was 107.5 minutes $^{(30)}$. The results presented in our series are comparable to the clinical outcome reported by Asiatic expert centers and the recently published meta-analysis. Moreover, when we analyze all patients that entered the study (including ESCC and BE-associated lesions) an en bloc resection rate of $96.9 \%, \mathrm{R} 0$ resection rate of $73.8 \%$ and curative resection rate of $70.8 \%$ was achieved.

The most common adverse effects of ESD are bleeding, perforation, and stenosis. The management of these complications is technically more difficult in the esophagus ${ }^{(15)}$. In the present series, two patients $(3 \%)$ had major intraoperative bleeding, requiring endoscopic approach with mechanical hemostasis with clips. Bleeding can also be observed at a rate that ranges from $0-22.8 \%$ of procedures ${ }^{(9,15,18)}$. We experienced one esophageal perforation $(1.5 \%)$ treated successfully by clips without impairing ESD resection. In Japanese expert centers esophageal perforation rate has been reported in up to $2 \%$ of the ESD cases ${ }^{(15,18,29)}$. Esophageal stricture may occur in $10 \%$ to $20 \%$ of patients undergoing esophageal $\mathrm{ESD}^{(15)}$. In our series, a total of six patients developed post-ESD stricture $(9.2 \%)$ with similar rates between the two groups. In all cases the resection site was greater than three quarters of circumference and were managed by dilation.

The change from the tunneling method to circumferential incision approach during esophageal ESD at our center occurred due to the additional training that the operator received in Japan in 2012. After this education, the adoption of the tunneling technique was implemented. ESD-T was carried out in our institution between 2009 and 2012 but can be considered as an emerging technique. Mastery of the technique is important as the use of the submucosal space for tunnel dissection has been proven to be effective for the treatment of large and even circumferential superficial lesions of the esophagus, peroral endoscopic myotomy (POEM), resection of subepithelial tumors and perhaps in the near future will enable interventions outside the gastrointestinal tract, including lymph node resection and removal of benign tumors in the mediastinum or abdominal cavity ${ }^{(31-33)}$. Modifications to ESD-T, including the performance of more than one submucosal tunnel have been described for more extensive and circumferential lesions ${ }^{(34-37)}$. Some studies suggest that ESD-T may have a higher operation efficacy compared to ESD-C in the treatment of extensive esophageal superficial neoplasms ${ }^{(32)}$, albeit we did not find differences in outcomes between these two techniques in our analysis.

This study is one of the largest series analyzed in the treatment of superficial esophageal neoplasms in Latin American countries, comparing two different esophageal ESD techniques. Nevertheless, this report is not without limitations. This is a single-center study based on retrospective data. A single operator with extensive training in the technique performed all procedures, which limits the generalizability of these results. It is not possible to rule out the learning curve effect on the analysis of clinical outcomes, especially in ESD-C, since from 2012 to the present, this has been the technique adopted in our center. Finally, the number of patients included in this series is relatively small and includes both patients with ESCC and Barrett's esophagus associated lesions. Hence, the small sample size and heterogeneous lesion types may have precluded the detection of potentially meaningful differences in outcomes. Therefore, the lack of a statistically significant difference may not necessarily exclude the possibility of clinically relevant differences. Future larger prospective comparative trials are needed to further corroborate our findings.

In conclusion, ESD performed via the tunneling method or via the conventional approach demonstrated to be equally feasible and safe in the treatment of superficial esophageal neoplasms. Both techniques had high rates of en bloc resection, $\mathrm{R} 0$ resection, and curative resections, and minimal adverse events. The choice of one technique over the other may be defined at the discretion of the endoscopist according to his or her experience and preference.

\section{ACKNOWLEDGMENT}

The authors are grateful to Mr. Marcelo Siqueira Valle for creating the illustrative figures included in this manuscript.

\section{Authors' contribution}

Arantes VN: conception, design, data collection and/or processing, analysis and interpretation, literature review, writing, supervision, critical review. Ribeiro TML and Ramos JA: design, data collection and/or processing, analysis and interpretation, literature review, writing. Guimarães RG: data collection and/ or processing. Yang D: analysis and interpretation, writing, critical review. Draganov PV: analysis and interpretation, writing, critical review.

\section{Orcid}

Tarso Magno Leite Ribeiro: 0000-0002-1370-6753.

Vitor N Arantes: 0000-0001-8000-5298.

Jonas Augusto Ramos: 0000-0003-4083-8425.

Peter V Draganov: 0000-0002-3922-0882.

Dennis Yang: 0000-0003-3038-4669.

Roberto Gardone Guimarães: 0000-0002-9657-6615. 
Ribeiro TML, Arantes VN, Ramos JA, Draganov PV, Yang D, Guimarães RG. Dissecção endoscópica submucosa com incisão circunferencial versus túnel submucoso no tratamento da neoplasia superficial do esôfago. Arq Gastroenterol. 2021;58(2):195-201.

RESUMO - Contexto - A dissecção endoscópica submucosa (DES) no tratamento da neoplasia superficial do esôfago está associada a uma alta taxa de ressecção R0 em bloco e baixa taxa de recorrência. Objetivo - O objetivo deste estudo é comparar o desempenho e os resultados clínicos da DES com incisão circunferencial (DES-C) versus com DES com túnel submucoso (DES-TS). Métodos - Estudo retrospectivo de banco de dados coletados prospectivamente de um centro especializado em DES, investigando pacientes consecutivos submetidos à DES por câncer de esôfago superficial, entre 2009 e 2018. DES-TS foi definida como a técnica de realizar primeiro incisões na mucosa seguida de tunelamento submucoso no sentido oral para anal. DES-C consistiu em completar uma incisão circunferencial seguida da dissecção submucosa. As principais variáveis do estudo incluíram taxas de ressecção em bloco e R0. Os resultados secundários incluíram características do procedimento, taxa de ressecção curativa, recorrência local e eventos adversos. Resultados - Um total de 65 procedimentos (23 DES-TS e 42 DES-C) foram realizados para CCE de esôfago (40; 61,5\%) e neoplasia associada ao EB $(25 ; 38,5 \%)$. Não houve diferenças estatisticamente significativas entre os pacientes submetidos a DES-TS versus DES-C nas taxas de ressecção em bloco ( $91,3 \%$ vs $100 \%, P=0,12)$, R0 (65,2\% vs 78,6\%, $P=0,24)$, taxas de ressecção curativa $(65,2 \%$ vs $73,8 \%, P=0,47)$ e tempo médio do procedimento ( $118,7 \mathrm{~min}$ com vs $102,4 \mathrm{~min}, P=0,35)$. Os eventos adversos para DES-TS e DES-C foram os seguintes: sangramento ( 0 vs $2,4 \% ; P=0,53)$, perfuração ( $4,3 \%$ vs $0 ; P=0,61)$, estenose esofágica ( $8,7 \%$ vs $9,5 \% ; P=0,31)$. A recorrência local foi encontrada em $8,7 \%$ após DES-TS e 2,4\% após DES-C $(P=0,28)$ em um seguimento médio de 8 e 2,75 anos, respectivamente $(P=0,001)$. Conclusão - DES-TS e DES-C demostram ser igualmente eficazes com perfil de segurança semelhante para o tratamento das neoplasias superficiais do esôfago.

Palavras-chave - Dissecção endoscópica submucosa; neoplasia superficial do esôfago; câncer de esôfago; câncer de células escamosas; esôfago de Barrett.

\section{REFERENCES}

1. Draganov PV, Gotoda T, Chavalitdhamrong D, Wallace MB. Techniques of endoscopic submucosal dissection: application for the Western endoscopist? Gastrointest Endosc. 2013;78:677-88.

2. Gotoda T, Kondo H, Ono H, Saito Y, Yamaguchi H, Saito D, Yokota T. A new endoscopic mucosal resection procedure using an insulation-tipped electrosurgical knife for rectal flat lesions: report of two cases. Gastrointest Endosc. 1999;50:560-63.

3. Sepesi B, Watson TJ, Zhou D, Polomsky M, Litle VR, Jones CE, et al. Are endoscopic therapies appropriate for superficial submucosal esophageal adenocarcinoma? An analysis of esophagectomy specimens. J Am Coll Surg. 2010;210:418-27.

4. Ishihara R, Iishi H, Uedo N, Takeuchi Y, Yamamoto S, Yamada T, et al. Comparison of EMR and endoscopic submucosal dissection for en bloc resection of early esophageal cancers in Japan. Gastrointest Endosc. 2008;68:1066-72.

5. Kim JS, Kim BW, Shin IS. Efficacy and safety of endoscopic submucosal dissection for superficial squamous esophageal neoplasia: a meta-analysis. Dig Dis Sci. 2014;59:1862-9

6. Shimizu Y, Takahashi M, Yoshida T, Ono S, Mabe K, Kato M, et al. Endoscopic resection (endoscopic mucosal resection/ endoscopic submucosal dissection) for superficial esophageal squamous cell carcinoma: current status of various techniques. Dig Endosc. 2013;25:13-9.

7. Takahashi H, Arimura Y, Masao H, Okahara S, Tanuma T, Kodaira J, et al. Endoscopic submucosal dissection is superior to conventional endoscopic resection as a curative treatment for early squamous cell carcinoma of the esophagus (with video). Gastrointest Endosc. 2010;72:255-64

8. Draganov PV, Wang AY, Othman MO, Fukami N. AGA Institute Clinical Practice Update: Endoscopic Submucosal Dissection in the United States. Clin Gastroenterol Hepatol. 2019;17:16-25.

9. Pimentel-Nunes P, Dinis-Ribeiro M, Ponchon T, Repici A, Vieth M, Ceglie A, et al. Endoscopic submucosal dissection: European Society of Gastrointestinal Endoscopy (ESGE) Guideline. Endoscopy. 2015;47:829-54.

10. Bourke MJ, Newhaus H, Bergman JJ. Endoscopic Submucosal Dissection: Indications and Application in Western Endoscopy Practice. Gastroenterology. 2018;154:1887-1900.

11. Arantes V, Albuquerque W, Dias CAF, Cabral MMDA, Yamamoto H. Standardized endoscopic submucosal tunnel dissection for management of early esophageal tumors (with video). Gastrointest Endosc. 2013;78:946-52.

12. Arantes V, Forero P, Yoshimura K, Toyonaga T. Advances in the management of early esophageal carcinoma. Rev Col Bras Cir. 2012;39:534-43.

13. Tsou YK, Chuang WY, Liu CY, Ohata K, Lin C-H, Lee M-S, et al. Learning curve for endoscopic submucosal dissection of esophageal neoplasms. Dis Esophagus. 2016;29:544-50.

14. Davydov M, Delektorskaya VV, Kuvshinov YP, Lisovsky M, Pirogov S, Udagawa $\mathrm{H}$ et al. Superficial and early cancers of the esophagus. Ann N Y Acad Sci. 2014;1325:159-69

15. Aadam AA, Abd S. Endoscopic submucosal dissection for superficial esophageal cancer. Dis Esophagus. 2018;31(7). DOI: 10.1093/dote/doy021.
16. Ma MX, Bourke MJ. Endoscopic submucosal dissection in the West: Curren status and future directions. Dig Endosc. 2018;30:310-20.

17. Chaves DM, Maluf Filho F, de Moura EG, Moura EGH, Santos MEL, Arrais LRG, et al. Endoscopic submucosal dissection for the treatment of early esophageal and gastric cancer--initial experience of a western center. Clinics (Sao Paulo). 2010;65:377-82.

18. Maple JT, Dayyeh BKA, Chauahan SS, Hwang JH, Manfredi M, Konda V, et al. Endoscopic submucosal dissection. Gastrointest Endosc. 2015;81:1311-25. DOI: $10.1016 /$ j.gie.2014.12.010

19. Fujishiro M, Kodashima S, Goto O, Ono S, Niimi K, Yamamichi N, et al. Endoscopic submucosal dissection for esophageal squamous cell neoplasms. Dig Endosc. 2009;21:109-15.

20. Linghu E, Feng X, Wang X, Meng J, Du H, Wang H. Endoscopic submucosal tunnel dissection for large esophageal neoplastic lesions. Endoscopy. 2013;45:60-2.

21. Kuwano H, Nishimura Y, Oyama T, Kato H, Kitagawa Y, Kusano M, et al Guidelines for Diagnosis and Treatment of Carcinoma of the Esophagus April 2012 edited by the Japan Esophageal Society. Esophagus. 2015;12:1-30.

22. The Paris endoscopic classification of superficial neoplastic lesions: esophagus, stomach, and colon: November 30 to December 1, 2002. Gastrointest Endosc. 2003;58:S3-43. DOI: 10.1016/s0016-5107(03)02159-x

23. Cotton PB, Eisen GM, Aabakken L, Baron TH, Hutter MH, Jacobson BC, et al. A lexicon for endoscopic adverse events: report of an ASGE workshop. Gastrointest Endosc. 2010;71:446-54

24. Li Y, Wang K, Shi Y, Zhu J, Cui R, Hejun Zhang, et al. Comparison of ShortTerm Efficacy Between Endoscopic Submucosal Tunnel Dissection and Endoscopic Submucosal Dissection in Treatment of Wide Esophageal Squamous Cell Carcinoma of Early Stage. J Clin Gastroenterol. 2020;54:512-16.

25. Gomercic C. Vanbiervliet G, Gonzalez JM, Saint-Paul MC, Garcès-Duran R, Garnier E, et al. Prospective randomized comparison of endoscopic submucosal tunnel dissection and conventional submucosal dissection in the resection of superficial esophageal/gastric lesions in a living porcine model. Endosc Int Open. 2015;3:E577-83.

26. Arantes V, Albuquerque W, Salles JM, Dias CAF, Alberti LR, Kahaleh M, et al. Effectiveness of unsedated transnasal endoscopy with white-light, flexible spectral imaging color enhancement, and lugol staining for esophageal cancer screening in high-risk patients. J Clin Gastroenterol. 2013;47:314-21.

27. Barret M, Cao DT, Beuvon F, Leblanc S, Terris B, Camus M, et al. Endoscopic submucosal dissection for early Barrett's neoplasia. United European Gastroenterol J. 2016;4:207-15.

28. Yang D, Coman RM, Kahaleh M, Waxman I, Wang AY, Sethi A, et al. Endoscopic submucosal dissection for Barrett's early neoplasia: a multicenter study in the United States. Gastrointest Endosc. 2017;86:600-7.

29. Daoud DC, Suter N, Durand M, Bouin M, Faulques B, Renteln DV, et al. Comparing outcomes for endoscopic submucosal dissection between Eastern and Western countries: A systematic review and meta-analysis. World J Gastroenterol. 2018;24:2518-36. 
30. Yang D, Zou F, Xiong S, Forde JJ, Wang Y, Draganov PV. Endoscopic submucosal dissection for early Barrett's neoplasia: a meta-analysis. Gastrointest Endosc. 2018;87:1383-93.

31. Chai NL, Li HK, Linghu EQ, Li ZS, Zhang ST, Bao Y, et al. Consensus on the digestive endoscopic tunnel technique. World J Gastroenterol. 2019;25:744-76.

32. Zhai YQ, Li HK, Linghu EQ. Endoscopic submucosal tunnel dissection for large superficial esophageal squamous cell neoplasms. World J Gastroenterol. 2016;22:435-45.

33. Martins RK, Ribeiro IB, DE Moura DTH, Hathorn KE, Bernardo WM, DE Moura EGH. Peroral (POEM) or surgical myotomy for the treatment of acalasia: a systematic review and meta-analysis. Arq Gastroenterol. 2020; 57:79-86.
34. Wang J, Zhu XN, Zhu LL, Chen WC, Ma YH, Gan T, Yang JL. Efficacy and safety of endoscopic submucosal tunnel dissection for superficial esophageal squamous cell carcinoma and precancerous lesions. World J Gastroenterol. 2018;24:2878-85.

35. Zhang W, Zhai Y, Chai N, Lighu E, Li H, Feng X. Single and double-tunnel endoscopic submucosal tunnel dissection for large superficial esophageal squamous cell neoplasms. Endoscopy. 2018;50:505-10.

36. Gan T, Yang JL, Zhu LL, Wang YP, Yang L, Wu JC. Endoscopic submucosal multi-tunnel dissection for circumferential superficial esophageal neoplastic lesions (with videos). Gastrointest Endosc. 2016;84:143-6.

37. Zhu LL, Wu JC, Wang YP, He D, Zhang WY, Gan T, Yang JL. Endoscopic Submucosal Single- or Multi-tunnel Dissection for Near-Circumferential and Circumferential Superficial Esophageal Neoplastic Lesions. Gastroenterol Res Pract. 2019;2019:2943232. 